\title{
Mortality surveillance and occupational hazards: the Solutia mortality experience 1980-94
}

\author{
James J Collins, Susan G Riordan
}

\begin{abstract}
Objectives-Several investigators argue that company wide mortalities for recent workers allow early identification of potential workplace hazards. Mortalities for recent workers were compared with published studies of workers with specific exposures in the same company to find whether mortality surveillance results could be used to identify previously unknown health effects from workplace hazards.

Methods-Relative risks for causes of death in published substance specific studies at the plants were compared with the relative risks in the mortality surveillance of workers 20 or more years after first being employed.

Results-As reported by other companies, low mortalities were found among workers in the mortality surveillance. The mortality surveillance reports often found no increased risk of disease at plants in which substance specific studies had found no effects. However, disease specific relative risks were not found by the mortality surveillance predictions of relative risks in the substance specific studies with increased risk.

Conclusion-Mortality surveillance is of limited use for identifying health effects from past workplace exposures to specific materials. The healthy worker and survivor effects, the failure to identify subsets of workers exposed to potentially toxic substances, the typically long induction period between exposure and disease, and the inability of recent mortality levels to reflect historical conditions all may make it difficult to use mortality surveillance to identify workplace hazards. Combining mortality surveillance with studies of workers with potentially toxic exposures helps identify occupational hazards.

(Occup Environ Med 2000;57:710-717)
\end{abstract}

Solutia, 10300 Olive Boulelvard, St Louis, Missouri 63166, USA J J Collins

Monsanto, 700 Chesterfield Parkway

North, Chesterfield, Missouri 63017, USA

S G Riordan

Correspondence to: Dr James J Collins james.j.collins@solutia.com

Accepted 23 June 2000
Keywords: mortality surveillance; occupational cancer; bladder cancer; leukaemia

Recent mortalities for an entire company have often been reported. ${ }^{1-12}$ We refer to these reports as mortality surveillance. Mortality surveillance provides an evaluation of recent mortality levels without examining specific exposures as is done in a formal study. Surveillance studies uniformly show low rates of total mortality and total cancer mortality for the workers studied, although occasionally rates of some causes of death are greater than expected.
Among other benefits, mortality surveillance may facilitate early identification of occupational hazards. ${ }^{1579-1113}$ However, the use of routine mortality surveillance for identifying occurrences of disease which are the result of workplace exposure has not been systematically evaluated. The healthy worker and survivor effects, the inability to identify subsets of workers exposed to potentially toxic substances, the failure to trace workers who leave employment for reasons other than retirement, the potentially long induction period between exposure and disease, and the fact that recent mortality levels do not necessarily reflect historical conditions all may make it difficult to use mortality surveillance to identify workplace hazards. We present the results of mortality surveillance for a company and compare results with past published studies of several plants in this company to find whether mortality surveillance is of use for identifying previously unknown health effects from workplace exposure.

\section{Materials and methods}

The population for our mortality surveillance is the 43339 workers who worked 1 or more days at any Solutia United States location between 1 January 1980 and 31 December 1994. Solutia was formally the chemical businesses of the Monsanto Company. An extensive number and variety of chemicals have been produced at these locations. Studies have been done examining some of these chemicals. ${ }^{14-32}$

Company personnel and payroll records provided demographic and work history data. For all eligible workers sex, race, birth date, hire date, date of end of employment, and whether waged or salaried were recorded. The completeness of the study population was evaluated by comparison with the employer's quarterly report on earnings, Internal Revenue Service form 941-schedule A. ${ }^{33}$ A sample of the study population was verified as being $99 \%$ complete. We followed guidelines for study conduct given by the Chemical Manufacturers Association. ${ }^{34}$

\section{FOLLOW UP OF VITAL STATUS}

Vital status was assessed through company records and the National Death Index. Employees collecting wages or retired employees receiving benefits on the last day of 1994 were assumed to be alive to the end of 1994 . Vital status was complete for $98 \%$ (42 459 of 43339 ) of the study population, and 2406 deaths were recorded.

Death certificates were requested from the respective states when not available in 
company records. All but two of the death certificates were obtained. Death certificates were coded independently by two nosologists according to the eighth revision of the international classification of diseases (ICD-8). Differences were resolved through discussion between the two nosologists.

STATISTICAL METHODS

Person-years for study subjects were accumulated across 5 year age and calendar year specific intervals beginning with the date of hire or 1 January 1980, whichever was later. Subjects continued to contribute person-years at risk until the earliest of the date lost to follow up, the date of death, or 31 December 1994. We limited the racial breakdown to white and non-white workers because of the small number of workers in some racial groups. We calculated standardised mortality ratios (SMRs) to compare mortalities with those of the United States population. ${ }^{35}$ We present common causes of death and causes which have been associated with occupational exposures. $^{36}$

We used all published studies which examined the mortalities of workers at any of our plants to compare with the findings of the mortality surveillance. When multiple studies reported on the same study population, we used only the most recent study. ${ }^{15} 1922 \quad 24252729-32$ We limited the comparison in the surveillance data to workers with 20 or more years since first employment to exclude recently employed workers.

\section{Results}

Table 1 presents the distribution of the 43339 workers included in the mortality surveillance by selected characteristics. The study population was mostly white $(85.6 \%)$ and male $(72.7 \%)$. The white and Hispanic people from table 1 were combined to form the white percentage noted. Most workers were salaried $(64.5 \%)$ which included administrative, technical and professional staff, clerks and secretaries, all workers at the general offices, and all workers at two plants after 1993 which reclassified all hourly workers to salaried. Of the workers $43.5 \%$ left the company before retirement and $24.2 \%$ were retired. More than $40 \%$ of the workers were employed before 1970 . Almost $70 \%$ of the workers were in production facilities.

The 43339 workers contributed a total of 525764 person years of observation for a mean follow up of 12.1 years. Table 2 presents the observed and expected deaths by cause for hourly and salaried workers by sex for the entire follow up period and 20 years since first employed. Male hourly workers had an SMR of 0.8 (95\% CI 0.8 to 0.9$)$ for all causes of death. Death rates for all cancer (SMR 0.9, 95\% CI 0.8 to 1.0 ) and heart disease (SMR $0.9,95 \%$ CI 0.8 to 1.0 ) were also below expected levels. Most individual cancer sites for hourly males were at or below expected levels with the exception of leukaemia (SMR 1.8, 95\% CI 1.1 to 2.6), large intestine (SMR 1.2, 95\% CI 0.9 to 1.6 ), bone (SMR 1.2, 95\% CI 0.0 to 6.6 ),
Table 1 Distribution of Solutia workers 1980-94 by selected characteristics

\begin{tabular}{|c|c|c|}
\hline Characteristic & $n$ & $\%$ \\
\hline \multicolumn{3}{|l|}{ Race: } \\
\hline White & 36415 & 84.0 \\
\hline Black & 5299 & 12.2 \\
\hline Hispanic & 687 & 1.6 \\
\hline Asian & 739 & 1.7 \\
\hline American Indian & 164 & 0.4 \\
\hline Other and unknown & 35 & 0.1 \\
\hline \multicolumn{3}{|l|}{ Sex: } \\
\hline Male & 31494 & 72.7 \\
\hline Female & 11845 & 27.3 \\
\hline \multicolumn{3}{|l|}{ Pay: } \\
\hline Hourly & 15026 & 34.7 \\
\hline Salary & 27964 & 64.5 \\
\hline Hourly to salary & 349 & 0.8 \\
\hline \multicolumn{3}{|l|}{ Working: } \\
\hline Currently employed & 14020 & 32.3 \\
\hline Left company (not retired) & 18834 & 43.5 \\
\hline Retired & 10485 & 24.2 \\
\hline \multicolumn{3}{|l|}{ Year of first employment: } \\
\hline$<1970$ & 17955 & 41.4 \\
\hline$\geqslant 1970$ & 25384 & 58.6 \\
\hline \multicolumn{3}{|l|}{ Location: } \\
\hline General offices & 13386 & 30.1 \\
\hline Carondolet & 541 & 1.3 \\
\hline Chocolate Bayou & 1730 & 4.0 \\
\hline Columbia & 714 & 1.6 \\
\hline Decatur & 2986 & 6.9 \\
\hline Fovil & 590 & 1.4 \\
\hline Greenwood & 2650 & 6.1 \\
\hline Indian Orchard & 3013 & 7.0 \\
\hline Nitro & 1017 & 2.3 \\
\hline Pensacola & 5566 & 12.8 \\
\hline Port Plastics & 1316 & 3.0 \\
\hline Queeny & 1657 & 3.8 \\
\hline Soda Springs & 751 & 1.7 \\
\hline Texas City & 2378 & 5.5 \\
\hline Trenton & 1194 & 2.8 \\
\hline All other & 3850 & 8.9 \\
\hline
\end{tabular}

and prostate (SMR 1.1, 95\% CI 0.7 to 1.6 ). The SMRs for non-malignant respiratory disease (SMR 0.5, 95\% CI 0.3 to 0.6 ) and accidents (SMR $0.6,95 \%$ CI 0.4 to 0.9 ) were below expected levels. The workers who were hired 20 or more years before the end of the study period had SMRs similar to all workers.

Male salaried workers had an SMR for all causes of death of 0.5 (95\% CI 0.5 to 0.5 ). Observed deaths for all cancer (SMR 0.6, 95\% CI 0.6 to 0.7 ) and all heart disease (SMR 0.6, $95 \%$ CI 0.5 to 0.6 ) were also less than expected. All individual sites of cancer and other causes of death were at or below expected levels. The SMRs for workers with 20 or more years since first employment were similar to the SMRs for all workers.

Female hourly workers had death rates (SMR $0.7,95 \%$ CI 0.6 to 0.8 ), cancer rates (SMR $0.795 \%$ CI 0.5 to 0.9 ), and heart disease rates (SMR $0.595 \%$ CI 0.3 to 0.5 ) which were less than the United States population. Death rates for motor vehicle accidents were greater than the United States population, although there was a deficit among women with 20 or more years since first employment. SMRs for individual cancer sites for hourly paid women were at or below expected levels with the exception of leukaemia (SMR 1.7, 95\% CI 0.3 to 4.9 ), and large intestine (SMR 1.1, 95\% CI 0.3 to 2.5 ). The SMRs for hourly paid women workers with 20 or more years since first employment were similar to the SMRs for all female workers paid hourly with the exception of stomach cancer (SMR $1.3,95 \%$ CI0.0 to 7.5$)$. 
Table 2 Solutia mortality surveillance standardised mortality ratios (SMR, 95\% CIs) for hourly and salaried workers for entire population and $\geqslant 20$ years induction latency period

\begin{tabular}{|c|c|c|c|c|}
\hline \multirow[b]{2}{*}{ Cause of death (ICD-9) } & \multicolumn{2}{|l|}{ Hourly workers } & \multicolumn{2}{|l|}{ Salaried workers } \\
\hline & $\begin{array}{l}\text { Entire population SMR } \\
(95 \% \mathrm{CI})\end{array}$ & $\begin{array}{l}\geqslant 20 \text { Induction latency } \\
\text { SMR }(95 \% \mathrm{CI})\end{array}$ & $\begin{array}{l}\text { Entire population } \\
\text { SMR }(95 \% \text { CI })\end{array}$ & $\begin{array}{l}\geqslant 20 \text { Induction latency } \\
\text { SMR }(95 \% \mathrm{CI})\end{array}$ \\
\hline \multicolumn{5}{|l|}{ Men: } \\
\hline All causes (001-999) & $0.8(0.8$ to 0.9$)$ & $0.8(0.8$ to 0.9$)$ & $0.5(0.5$ to 0.5$)$ & $0.5(0.5$ to 0.6$)$ \\
\hline All cancers $(140-208)$ & $0.9(0.8$ to 1.0$)$ & $0.9(0.8$ to 1.0$)$ & $0.6(0.6$ to 0.7$)$ & $0.6(0.6$ to 0.7$)$ \\
\hline Oesophagus $(150)$ & $0.8(0.4$ to 1.5$)$ & $1.0(0.5$ to 1.7$)$ & $0.3(0.1$ to 0.8$)$ & $0.3(0.0$ to 0.8$)$ \\
\hline Stomach $(151)$ & $1.0(0.5$ to 1.6$)$ & $1.0(0.5$ to 1.7$)$ & $0.4(0.1$ to 0.9$)$ & $0.3(0.0$ to 0.8$)$ \\
\hline Large intestine (153) & $1.2(0.9$ to 1.6$)$ & $1.1(0.8$ to 1.6$)$ & $0.8(0.6$ to 1.2$)$ & $0.9(0.6$ to 1.2$)$ \\
\hline Liver and biliary passages $(155-156)$ & $0.6(0.2$ to 1.2$)$ & $0.7(0.2$ to 1.5$)$ & $0.2(0.0$ to 0.6$)$ & $0.1(0.0$ to 0.6$)$ \\
\hline Larynx (161) & $0.0(0.0$ to 0.6$)$ & $0.0(0.0$ to 0.7$)$ & $0.3(0.0$ to 1.1$)$ & $0.2(0.0$ to 1.0$)$ \\
\hline Bronchus, trachea, lung (162) & $0.9(0.8$ to 1.1$)$ & $0.9(0.8$ to 1.1$)$ & $0.6(0.5$ to 0.7$)$ & $0.6(0.5$ to 0.7$)$ \\
\hline All other respiratory $(160,163,164,165)$ & $0.0(0.0$ to 0.5$)$ & $0.0(0.0$ to 5.8$)$ & $0.2(0.0$ to 0.8$)$ & $0.1(0.0$ to 0.8$)$ \\
\hline Prostate $(185)$ & $1.1(0.7$ to 1.6$)$ & $1.0(0.7$ to 1.5$)$ & $0.6(0.4$ to 1.0$)$ & $0.6(0.3$ to 0.9$)$ \\
\hline Bladder $(188,189.3,189.4,189.8,189.9)$ & $0.8(0.3$ to 1.6$)$ & $0.6(0.2$ to 1.4$)$ & $0.5(0.2$ to 1.3$)$ & $0.6(0.2$ to 1.4$)$ \\
\hline Malignant melanoma of skin (172) & $0.7(0.2$ to 1.7$)$ & $0.6(0.1$ to 1.7$)$ & $0.9(0.4$ to 1.6$)$ & $0.8(0.3$ to 1.7$)$ \\
\hline Bone $(170)$ & $1.2(0.0$ to 6.6$)$ & $0.0(0.0$ to 6.4$)$ & $0.0(0.0$ to 3.2$)$ & $0.0(0.0$ to 5.0$)$ \\
\hline Leukaemia (204-208) & $1.8(1.1$ to 2.6$)$ & $1.5(0.8$ to 2.4$)$ & $0.7(0.4$ to 1.3$)$ & $0.7(0.4$ to 1.4$)$ \\
\hline All heart disease $(390-398,402,404,410-429)$ & $0.9(0.8$ to 1.0$)$ & $0.9(0.8$ to 1.0$)$ & $0.6(0.5$ to 0.6$)$ & $0.6(0.5$ to 0.6$)$ \\
\hline Non-malignant respiratory disease $(460-519)$ & $0.5(0.3$ to 0.6$)$ & $0.5(0.4$ to 0.7$)$ & $0.3(0.2$ to 0.5$)$ & $0.3(0.2$ to 0.5$)$ \\
\hline Motor vehicle accidents (E810-825) & $1.0(0.7$ to 1.4$)$ & $1.1(0.6$ to 1.7$)$ & $0.3(0.2$ to 0.5$)$ & $0.6(0.3$ to 1.0$)$ \\
\hline All other accidents (E800-807,E826-949) & $0.6(0.4$ to 0.9$)$ & $0.7(0.4$ to 1.1$)$ & $0.3(0.2$ to 0.5$)$ & $0.4(0.2$ to 0.7$)$ \\
\hline \multicolumn{5}{|l|}{ Women: } \\
\hline All causes $(001-999)$ & 0.7 (0.6 to 0.8$)$ & $0.6(0.5$ to 0.8$)$ & $0.6(0.5$ to 0.7$)$ & $0.7(0.5$ to 0.8$)$ \\
\hline All cancers $(140-208)$ & $0.7(0.5$ to 0.9$)$ & $0.6(0.4$ to 0.9$)$ & $0.9(0.7$ to 1.0$)$ & $0.8(0.6$ to 1.1$)$ \\
\hline Oesophagus (150) & $0.0(0.0$ to 5.8$)$ & $0.0(0.0$ to 8.3$)$ & $1.1(0.0$ to 6.2$)$ & $1.8(0.0$ to 10.2$)$ \\
\hline Stomach (151) & $0.9(0.0$ to 5.0$)$ & $1.3(0.0$ to 7.5$)$ & $1.1(0.1$ to 3.9$)$ & $2.0(0.2$ to 7.1$)$ \\
\hline Large intestine (153) & $1.1(0.3$ to 2.5$)$ & $0.9(0.2$ to 2.5$)$ & $0.9(0.4$ to 1.8$)$ & $0.9(0.2$ to 2.1$)$ \\
\hline Liver and biliary passages $(155-156)$ & $0.0(0.0$ to 3.0$)$ & $0.0(0.0$ to 4.2$)$ & $0.0(0.0$ to 1.8$)$ & $0.0(0.0$ to 3.1$)$ \\
\hline Larynx (161) & $0.0(0.0$ to 13.9$)$ & $0.0(0.0$ to 19.2$)$ & $0.0(0.0$ to 9.2$)$ & $0.0(0.0$ to 15.1$)$ \\
\hline Bronchus, trachea, lung (162) & $0.9(0.5$ to 1.5$)$ & $0.8(0.4$ to 1.5$)$ & $0.9(0.5$ to 1.3$)$ & $1.0(0.6$ to 1.6$)$ \\
\hline All other respiratory $(160,163,164,165)$ & $0.0(0.0$ to 9.2$)$ & $0.0(0.0$ to 13.2$)$ & $0.0(0.0$ to 5.8$)$ & $0.0(0.0$ to 10.3$)$ \\
\hline Breast $(174,175)$ & $0.5(0.2$ to 1.0$)$ & $0.5(0.2$ to 1.3$)$ & $0.7(0.4$ to 1.1$)$ & $0.4(0.1$ to 0.8$)$ \\
\hline Bladder $(188,189.3,189.4,189.8,189.9)$ & $0.0(0.0$ to 8.0$)$ & $0.0(0.0$ to 10.5$)$ & $0.0(0.0$ to 4.9$)$ & $0.0(0.0$ to 7.6$)$ \\
\hline Malignant melanoma of skin (172) & $0.0(0.0$ to 4.7$)$ & $0.0(0.0$ to 7.8$)$ & $0.6(0.0$ to 3.4$)$ & $1.4(0.0$ to 7.6$)$ \\
\hline Bone $(170)$ & $0.0(0.0$ to 31.3$)$ & $0.0(0.0$ to 58.6$)$ & $0.0(0.0$ to 16.5$)$ & $0.0(0.0$ to 42.2$)$ \\
\hline Leukaemia (204-208) & $1.7(0.3$ to 4.9$)$ & $1.8(0.2$ to 6.5$)$ & $1.5(0.5$ to 3.5$)$ & $1.9(0.4$ to 5.5$)$ \\
\hline All heart disease $(390-398,402,404,410-429)$ & $0.5(0.3$ to 0.5$)$ & $0.5(0.3$ to 0.9$)$ & $0.7(0.4$ to 1.0$)$ & $0.7(0.4$ to 1.0$)$ \\
\hline Non-malignant respiratory disease $(460-519)$ & $0.8(0.3$ to 1.5$)$ & $0.8(0.3$ to 1.7$)$ & $0.7(0.3$ to 1.2$)$ & $0.8(0.4$ to 1.6$)$ \\
\hline Motor vehicle accidents (E810-825) & $1.7(0.7$ to 3.5$)$ & $0.8(0.0$ to 4.2$)$ & $0.5(0.2$ to 1.2$)$ & $0.5(0.0$ to 2.6$)$ \\
\hline All other accidents (E800-807,E826-949) & $0.7(0.1$ to 2.4$)$ & $0.0(0.0$ to 2.8$)$ & $0.6(0.2$ to 1.7$)$ & $0.5(0.0$ to 2.8$)$ \\
\hline \multicolumn{5}{|l|}{ People, person-years, and deaths: } \\
\hline People at risk & 15026 & 6853 & 27964 & 13354 \\
\hline Person-years & 189658 & 70377 & 336106 & 130526 \\
\hline Total deaths & 1325 & 1063 & 1079 & 845 \\
\hline
\end{tabular}

The SMRs for salaried women workers were very similar to waged women workers with low death rates (SMR 0.6, 95\% CI 0.5 to 0.7), cancer rates (SMR 0.9, 95\% CI 0.7 to 1.0 ), and heart disease rates (SMR $0.7,95 \%$ CI 0.4 to 1.0) relative to the United States population. Cancer SMRs were at or below expected levels with the exception of leukaemia (SMR 1.5, $95 \%$ CI 0.5 to 3.5 ), oesophagus (SMR 1.1, $95 \%$ CI 0.0 to 6.2 ), and stomach (SMR 1.1, $95 \%$ CI 0.1 to 3.9 ). The SMRs for salaried women workers 20 or more years since first employment were generally similar to the SMRs for all salaried women workers with the exceptions of stomach cancer (SMR 2.0, 95\% CI 0.2 to 7.1 ) and malignant melanoma of the skin (SMR $1.4,95 \%$ CI 0.0 to 7.6 ).

We identified nine studies at six different plants which examined a total of 26 hypothesised outcomes. ${ }^{15} 192224252729-32$ Figure 1 shows the inclusion criteria on years of employment for workers in these nine studies and our mortality surveillance. Only a recent study by Blair et al, which includes workers employed between 1952 and 1983, overlaps with the employment inclusion criterion of surveillance, or employment between 1980 and 1994. The remaining eight studies had study employment inclusion criterion several years earlier than the employment criterion for surveillance. The percentages of workers in the surveillance studies ranged from $72 \%$ for the study of Blair $e t a l^{30}$ to $7 \%$ for the study of Fingerhut et al..$^{24}$ We compared the surveillance results for workers with 20 or more years since first employment with published studies in table 3.

In the early 1950 s, the report of several bladder cancers at our Nitro and Queeny plants among workers with potential exposure to p-aminobiphenyl (PAB) led to the elimination of the use of $\mathrm{PAB}$ at the plants and routine cystoscopic examination of the exposed workers. $^{14}$ A study of these plants found increased rates of bladder tumours with an estimated relative risk of 27.1 (95\% CI 11.7 to 53.4) and concluded that exposure to PAB increases the risk of bladder cancer. ${ }^{15} 2831$ The number of bladder cancers reported in the recent surveillance reports at both plants were greater than expected but were based on only one case at Nitro (SMR 1.6, 95\% CI 0.0 to 8.8) and two cases at Queeny (SMR 1.9, 95\% CI 0.2 to 7.0). These three deaths from bladder cancer occurred among workers with potential exposure to PAB at these plants. Only 63 workers (52 from Nitro and 11 from Queeny) in the study by Melick et $a l^{15}$ were included in the surveillance.

Studies in the late 1970s of workers at our Indian Orchard plant reported rates of certain digestive and genitourinary cancers which were greater than rates in the state (Stanislawczyk K, 
$\% \ln$ surveillance study

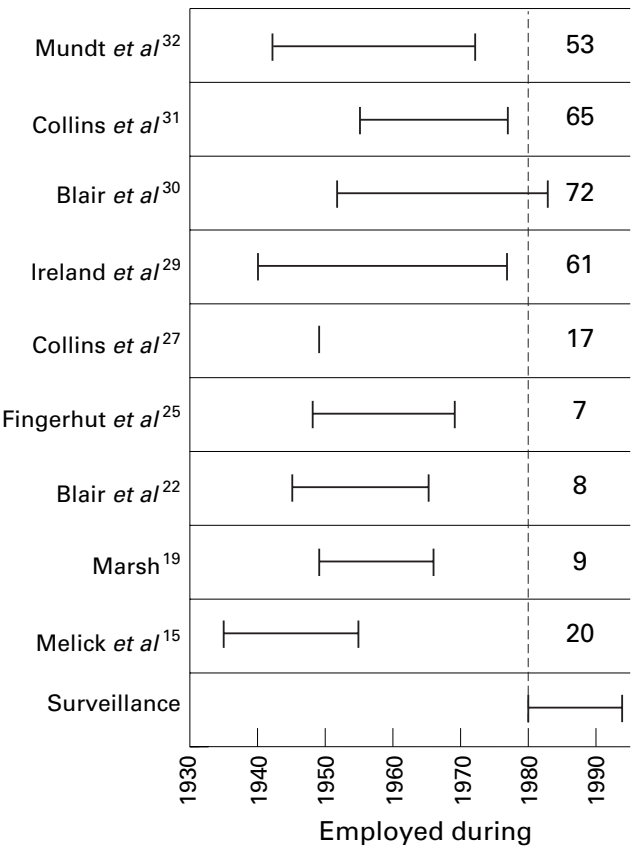

Figure 1 Employment criteria for workers in the separate studies, and the percentage of workers in each who are in our Solutia surveillance mortality study.

Kaminski R, Spirtas R; unpublished NIOSH report, May, 1978). A subsequent study by Marsh $^{19}$ examined these disease clusters and attempted to link them with occupational exposures. This study found that the observed number of genitourinary tract cancers (SMR $1.795 \%$ CI 1.1 to 2.5 ) and cancers of the digestive organs and peritoneum (SMR 1.3 95\% CI 0.9 to 1.7 ) were greater than expected, but could not be related to exposures at the plant. In the surveillance data, the observed number of cancers of the genitourinary tract were less than expected (SMR 0.3, 95\% CI0.0 to 0.8), whereas the observed number of cancers of digestive organs and peritoneum were slightly greater than expected (SMR $1.295 \%$ CI0.0 to 6.8). However, all four deaths from genitourinary tract cancer and 24 of the 26 deaths from cancers of the digestive organs and peritoneum occurred among workers who were included in the study of Marsh, ${ }^{19}$ and 224 workers in that study were included in the surveillance.

Blair et $a l^{2}$ examined risks of respiratory cancer for workers exposed to formaldehyde in 10 plants in the United States including our Indian Orchard plant. The authors concluded that the number of lung cancers found were slightly greater than expected among formaldehyde workers (SMR 1.1, 95\% CI 1.0 to 1.3 ) but did not seem to be related to the level of exposure. The surveillance results of the Indian Orchard plant, that included 218 workers in the study of Blair et al, found fewer lung cancers than expected (SMR 0.6, 95\% CI 0.4 to 0.9 ). ${ }^{22}$

In 1991, Fingerhut et $a 2^{425}$ reported the results of a mortality study of workers with potential exposure to dioxin at 12 plants throughout the United States. Workers with potential exposure to dioxin at our Nitro and Krummrich plants were included in this study. This study found high rates of soft tissue sarcoma and lung cancer among workers with more than 1 year of potential exposure and more than 20 years since first exposure. Fingerhut et al concluded that the SMRs for lung cancer and soft tissue sarcoma may be related to dioxin exposure. Lung cancer SMRs in the epidemiology study of Fingerhut et al were 1.4 (95\% CI 0.8 to 2.4 ) for the Nitro plant compared with 0.6 (95\% CI 0.2 to 1.3$)$ in the surveillance results. For the Krummrich workers in the study by Fingerhut et al the lung cancer SMR was 2.4 (95\% CI 0.5 to 7.0$)$ based on only three cases compared with an SMR of 0.9 (95\% CI 0.5 to 1.4$)$ in the surveillance results. There were two deaths reported for soft tissue sarcoma in the study of Fingerhut et al among workers at the Nitro plant (SMR 15.2, $95 \%$ CI 1.9 to 55.6) but no soft tissue sarcomas at the Krummrich plant. The surveillance data at both Nitro and Krummrich found no deaths from soft tissue sarcoma although far less than one death was expected at each location. Only 43 workers (36 from Nitro and seven from Krummrich) in the study of Fingerhut $e t$ al were included in the surveillance. The two deaths from soft tissue sarcoma at the Nitro plant occurred in 1969 and thus were not eligible for the surveillance study.

In 1949 there was an accidental release of a chemical mixture later recognised as containing dioxins. ${ }^{17} 2027$ One hundred and twenty of the workers involved in the clean up of this release developed chloracne, an indication of high exposure to dioxin. Some of the workers who developed chloracne also had potential exposure to PAB. The most recent of these studies $^{27}$ found that observed deaths from soft tissue sarcoma (SMR 6.7, 95\% CI 1.4 to 19.4 ) and bladder cancer (SMR 6.8, 95\% CI 3.9 to 11.1) exceeded expected cases among these workers. The authors concluded that the increased risk of bladder cancer was mostly likely the result of exposure to $\mathrm{PAB}$, and the increased risk of soft tissue sarcoma may be the result of exposures at the plant. There were no deaths from soft tissue sarcomas (SMR 0.0 $95 \%$ CI 0.0 to 121.0 ) reported in the surveillance reports as none of the deaths from soft tissue sarcoma in the study of Collins $e t a l^{27}$ met the inclusion criteria for the surveillance report and no new cases occurred in the additional surveillance follow up. Only one death from bladder cancer occurred in the surveillance report (SMR 1.6 95\% CI 0.0 to 8.8) and this worker had potential exposure to PAB and was included in the study by Collins et al. In that study 128 workers were included in the surveillance results.

Ireland et al examined workers employed in departments that used benzene at our Krummrich plant. ${ }^{29}$ They found more deaths among benzene production workers than expected for leukaemias (SMR 2.3, 95\% CI 0.7 to 5.3 ) and multiple myeloma (SMR 3.2, 95\% CI 0.7 to 9.4) and concluded that these findings may result from exposure to benzene. All groups of workers at the plant in the study of Ireland $e t$ 


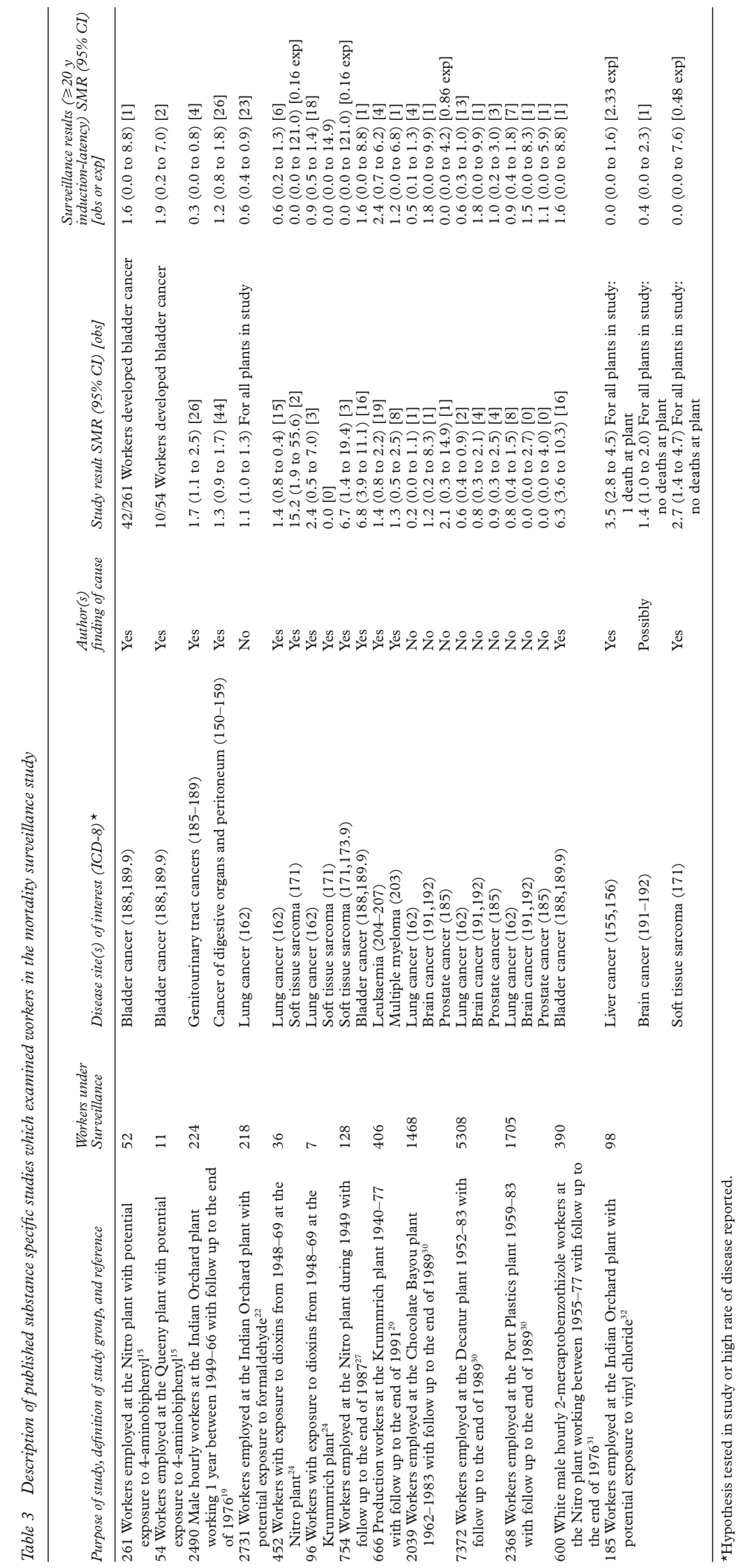

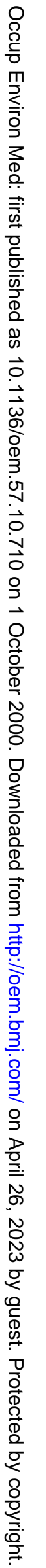


$a l^{29}$ had more deaths than expected for both leukaemias (SMR 1.4, 95\% CI 0.8 to 2.2 ) and multiple myeloma (SMR 1.3, 95\% CI 0.5 to 2.5). The surveillance results found that deaths from leukaemia (SMR 2.4, 95\% CI 0.7 to 6.2 ) and multiple myeloma (SMR 1.2, 95\% CI 0.0 to 6.8) exceeded expected numbers. In the study of Ireland et al, 406 workers were included in the surveillance results.

Blair et $a l^{30}$ completed a United States industry wide study of workers exposed to acrylonitrile at eight plants. Three Solutia plants or former plants were included in that study. Blair et al concluded that exposure to acrylonitrile did not increase the relative risk for most cancers of interest including cancer of the prostate and brain. A high relative risk of lung cancer was found in the highest exposure category, but exposure-response analysis did not provide strong or consistent evidence of causal association. The SMRs for cancers of the lung, prostate, and brain for the three Solutia plants in the study of Blair et al are consistent with these conclusions. The SMRs for these three cancer sites in the surveillance results are similar to the findings of Blair et al and consistent with United States rates of cancer. In the study of Blair et al, 8418 workers (1468 from Chocolate Bayou, 5308 from Decatur, and 1705 from Port Plastics) were included in the surveillance.

Studies of workers exposed to 2-mercaptobenzothiazole (MBT) at our Nitro plant found that there was no association between exposure to MBT and most cancers. ${ }^{28}{ }^{31}$ However, MBT workers exposed to $\mathrm{PAB}$ had increased rates of bladder cancer. The authors conclude that the increased risk of bladder cancer was mostly likely the result of the exposure to PAB. The bladder cancer SMR among all workers at the Nitro plant in the study was 6.3 (95\% CI 3.6 to 10.3$)$. The surveillance study found an SMR of $1.6(95 \%$ CI 0.0 to 8.8 ) based on a single death. This worker who died of bladder cancer was included in the study of Collins et al, and had potential exposure to PAB. ${ }^{31}$ Of the workers in the study of Collins et al 390 were included in the surveillance results.

An industry wide study of vinyl chloride workers at 37 plants included our Indian Orchard workers. ${ }^{16182632}$ The authors of the most recent study, Mundt et a $\beta^{2}$ concluded that the observed numbers of liver cancers, mostly from angiosarcoma, and soft tissue sarcoma were greater than expected and probably related to exposure to vinyl chloride. The number of brain cancers were also greater than expected and were probably not related to exposure to vinyl chloride. Mundt et al do not report observed and expected deaths for the Indian Orchard plant, but did report one death from angiosarcoma, and no deaths from either soft tissue sarcoma or brain cancer among the 226 workers exposed to vinyl chloride at this plant. The death from liver cancer was included in the surveillance study but this cause of death was coded in the ICD-8 as a secondary malignant neoplasm of the liver. However, hemangiosarcoma of liver was listed on the death certificate and the ICD-9 codes

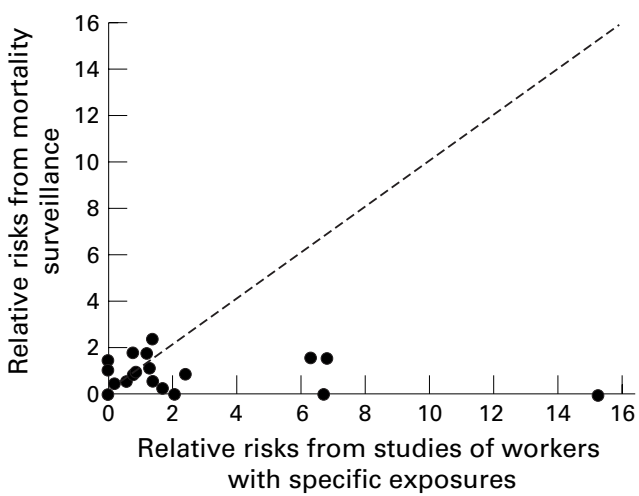

Figure 2. Scatterplot of the relative risks of causes of death featured in the specific exposure studies with the relative risks in our surveillance report for workers $\geqslant 20$ years after first employment, and the line indicating perfect correspondence between them.

this death as a liver cancer. There were no liver cancers reported in the surveillance study with 2.3 liver cancer deaths expected. Also, no brain cancers or deaths from soft tissue sarcoma were reported in the surveillance results. The surveillance results included 98 workers who were in the study by Mundt et al.

We plotted the study relative risks for causes of death which are causally evaluated in the studies with the relative risk in the surveillance population in figure $2 .^{1924252729-31}$ Three studies could not be included in this figure because either there were no relative risks presented, ${ }^{15}$ or the relative risks were not presented by plant. $^{22}{ }^{32}$ There were 20 causes of death evaluated in the six studies included. The dotted line in figure 2 represents perfect correspondence between the relative risks in the surveillance and study results. The surveillance studies are somewhat predictive of the study results, which have relative risks close to 1.0 . However, the four study findings with relative risks greater than 6.0 have surveillance findings which are close to the null. ${ }^{24} 2731$

\section{Discussion}

The workers in the surveillance study had low rates of total mortality, heart disease, accidents, and cancer. The low mortalities in our surveillance, particularly for non-cancer causes of death, probably reflect in part the healthy worker and the healthy survivor effects. The healthy worker effect refers in part to the initial selection of relatively healthy people at the time of employment. ${ }^{37}$ The healthy survivor effect is attributed to the tendency of the least healthy workers to leave the active workforce. ${ }^{38}$ Both of these effects may impact the mortalities of the surveillance populations. In our study, 15367 workers were employed in the last 15 years of follow up and the remaining 27972 workers are a censured population as they had to be in the active Solutia workforce in 1980 to be included. The potential biases associated with the healthy worker effect diminish with time since employment and are less important for interpreting cancer mortalities. ${ }^{37}$ The potential impact of the healthy survivor effect is impossible to evaluate as our surveillance report has no information on workers who left employment 
before 1980. Thus, mortalities of recent workers may not be useful for evaluating safety of the workplace in the past, discovering current hazards that produce disease with a protracted induction period, or that produce disease in a small portion of the population .

The mortalities of long term workers are the most useful in mortality surveillance for detecting possible work related effects in the past. The rates observed in our surveillance report for the entire company do not indicate widespread increased rates of cancer among current workers. With the exception of increased rates of leukaemia, mortality from cancer, non-malignant respiratory disease, heart disease, and accidents were comparable with or lower than mortalities for the United States population at each plant examined. This is similar to findings in other industrial groups with the exception of high rates of leukaemia in our surveillance. These high rates occurred at a single plant. The workers at this plant have been subject of two studies on benzene which has been related to increased risk of acute nonlymphatic leukaemia. ${ }^{23} 29$

Mortality surveillance by design focuses on the mortalities of recent workers. However, substance specific studies which typically consider a long disease induction period focus on the mortalities of workers in earlier times. We found that our surveillance results are not predictive of the causal findings from our studies. This is not surprising as the studies mostly examined workers not included in the mortality surveillance. The workers in the studies were employed during periods of generally higher exposures to different substances than the population in the mortality surveillance. Teta et $a l^{7}$ mention that large increases in mortality, especially for rare diseases in subpopulations in a plant can often be found in surveillance data. Thus, Teta et al are able to detect excess liver cancers in their surveillance data at a plant with exposures to vinyl chloride. We were successful in identifying high rates of leukaemia and multiple myeloma at our plant in a benzene study, ${ }^{29}$ bladder cancer at our plant in a $\mathrm{PAB}$ study, ${ }^{31}$ and a hemangiosarcoma at our plant in a vinyl chloride study $^{32}$ from our surveillance results. However, it is doubtful that these surveillance findings of themselves would have initiated further study as the relative risks were small and imprecise and thus could not be distinguished from numerous false positive findings present in assessments of multiple causes of death at many plants.

Although mortality surveillance alone may not be useful for identifying workplace hazards, it can be used for setting research priorities, investigating disease clusters, and providing data for substance specific studies. ${ }^{13} 39$ Mortality surveillance in combination with substance specific studies can be useful in assessing whether workplace place hazards identified in the past are still producing risk of disease in the current workforce.

\section{Conclusion}

It has been argued that mortality surveillance may provide an early indication of an occupational hazard. Although there have been examples in which surveillance reports have been useful in identifying hazards, our plant surveillance reports by themselves were of limited value in highlighting increased risk of disease from past occupational hazards. We conclude that mortality surveillance should be combined with substance studies to evaluate workplace hazards and provide credible assessments of risk of disease among current and past workers.

1 Pell S, O'Berg MT, Karrh BW. Cancer epidemiologic surveillance in the DuPont Company. $f$ Occup Med 978;20:725-40.

2 Divine BJ, Barron V, Kaplan SD. Texaco mortality study: I. mortality among refinery, petrochemical, and research workers. F Occup Med 1985;27:445-7.

3 Hanis NM, Shallenberger LG, Donaleski DL, et al. A retrospective mortality study of workers in three major U.S. refineries and chemical plants. F Occup Med 1985;27:28392.

4 Pifer JW, Hearne FT, Friedlander BR, et al. Mortality study of men employed at a large chemical plant, 1972-82. F Occup Med 1986;28:438-44.

5 Teta MJ, Ott MG, Schnatter AR. Population based mortality surveillance in carbon products manufacturing plants. Br F Ind Med 1987;44:344-50.

6 Bond GG, McLaren EA, Cartmill JB, et al. Mortality among female employees of a chemical company. Am $\mathcal{F}$ Ind Med
1987;12:563-78.

7 Teta MJ, Schnatter AR, Ott MG, et al. Mortality surveillance in a large chemical company: the Union Carbide Corporation experience, 1974-83. Am f Ind Med 1990;17:435-47.

8 Shallenberger LG, Acquavella JF, Donaleski D. An updated mortality study of workers in three major United States refineries and chemical plants. Br f Ind Med 1992;49:34554

9 Olsen GW, Lacy SE, Cartmill JB, et al. Half-century of cause-specific mortality experience of chemical manufacturing employees. Am f Ind Med 1994;26:203-19.

10 Tsai SP, Gilstrap EL, Cowles SR, et al. Long term follow up mortality study of petroleum refinery and chemical plant employees. Am f Ind Med 1996;29:75-87.

11 Divine BJ, Hartman CM, Wendt JK. Update of the Texaco mortality study 1947-93: part I. Analysis of overall patterns of mortality among refining, research, and petrochemical workers. Occup Environ Med 1999;56:167-73.

12 Divine BJ, Hartman CM, Wendt JK. Update of the Texaco mortality study 1947-93: part II. Analysis of specific causes of death for white men employed in refining, research, and of death for white men employed in refining, research,

13 Tsai SP, Dowd CM, Cowles SR, et al. Prospective morbidity surveillance of Shell refinery and petrochemical employees. Br f Ind Med 1991;48:155-63.

14 Melick WF, Escue HM, Naryka JJ, et al. The first reported cases of human bladder tumors due to new carcinogenxenylamine. F Urol 1955;74:760-6.

15 Melick WF, Naryka JJ, Kelly RE. Bladder cancer due to exposure to para-aminobiphenyl: a 17 year followup. $\mathcal{F}$ Urol 1971;106:220-6.

16 Tabershaw IR, Gaffey WR. Mortality study of workers in the manufacture of vinyl chloride and polyvinyl chloride workers. F Occup Med 1974;16:509-18.

17 Zack JA, Suskind RR. The mortality experience of workers exposed to tetrachlorodibenzodioxin in a trichlorophenol process accident. F Occup Med 1980;22:11-14.

18 Crooper WC. Epidemiologic study of vinyl chloride workers: mortality through December 31, 1972. Environ Health Perspect $1981 ; 41: 101-6$.

19 Marsh G. Mortality among workers from a plastics producing plant: a matched case-control study nested in a retrospective cohort study. $\mathcal{F}$ Occup Med 1983;25:21930

20 Zack JA, Gaffey WR. A mortality study of workers employed at the Monsanto company plant in Nitro, West Virginia. In: Tucker RE, Young AL, Grey AP, eds. Human and environmental risks of chlorinated dioxins and related compounds. Plenum Press, New York, 1983:575-91.

21 Suskind RR, Hertzberg VS. Human health effects of 2,4,5-T and its toxic contaminants. $\mathcal{F} A M A$ 1984;251: 2372-80.

22 Blair A, Stewart P, O’Berg M, et al. Mortality among industrial workers exposed to formaldehyde. $\mathcal{F}$ Nat Cancer Inst 1986;76:1071-84.

23 Wong O. An industry wide mortality study of chemical workers occupationally exposed to benzene. II Dose response analyses. Brf Ind Med 1987;44:382-95.

24 Fingerhut MA, Halperin WE, Marlow DA, et al. Mortality among US workers employed in the production of chemicals among US workers employed in the production of chemicals
contaminated with 2,3,7,8-tetrachlorodibenzo-p-dioxin (TCDD). Cincinnati, Ohio: NIOSH, 1991. (NTIS PB 91-125971.) 
25 Fingerhut MA, Halperin WE, Marlow DA, et al. Cancer mortality in workers exposed to 2,3,7,8-tetrachlorodibenzo-pdioxin. N Engl f Med 1991;324:212-18.

26 Wong $\mathrm{O}$, Whorton MD, Foliart DE, et al. An industry-wide epidemiologic study of vinyl chloride workers, 1942-82. Am f Ind Med 1991;20:317-34.

27 Collins JJ, Strauss ME, Levinskas GJ, et al. The mortality experience of workers exposed to 2,3,7,8 tetrachlorodibenzo-p-dioxin in a trichlorophenol process accident. Epidemiology 1993;4:7-13.

28 Strauss ME, Barrick ED, Bannister RM. Mortality experience of employees exposed to 2-mercaptobenzothiazole at a chemical plant in Nitro, West Virginia. $\mathrm{Br} \mathcal{F}$ Ind $\mathrm{Med}$ 1993;50:888-93.

29 Ireland B, Collins JJ, Buckley CF, et al. Cancer mortality among workers with benzene exposure. Epidemiology 1997; 8:318-20.

30 Blair A, Stewart PA, Zaebst DD, et al. Mortality of industrial workers exposed to acrylonitrile. Scand 7 Work Environ Health 1998;2(suppl):25-41.

31 Collins JJ, Strauss ME, Riordan SG. The mortality rates of workers at the Nitro plant with exposure to 2-mercaptobenzothialzole Occup Environ Med 1999;56: 667-71.
32 Mundt KA, Dell LD, Austin RP, et al. Historical cohort study of 10109 men employed in the North American chloride industry 1942-72: update of cancer mor-

33 Marsh GM, Enterline PE. A method for verifying the completeness of cohorts used in occupational mortality studies f Occup Med 1979;21:665-70.

34 Chemical Manufacturers Association's Epidemiology Task Group. Guidelines for good epidemiology practices for occupational and environmental epidemiologic research. $\mathcal{F}$ Occup Med 1991;33:1221-9.

35 Marsh GM, Preininger M. OCMAP. A user oriented occupational cohort mortality analysis program. The American Statistician 1980;34:245.

36 Doll R, Peto R. The causes of cancer: quantitative estimates of avoidable risks of cancer in the United States today. Oxford University Press, New York 1981.

37 Checkoway H, Pearce N, Crawford-Brown DJ. Research methods in occupational epidemiology. Oxford University methods in occupational
Press, New York, 1989 .

38 Arrighi HM, Hertz-Picciotto I. The evolving concept of the healthy worker survivor effect. Epidemiology 1994;2:189-96.

39 Collins JJ, Barbela T, Huebner WW, et al. A framework for addressing health issues in or near a manufacturing facility. f Environ Occup Med 2000;42:163-70. 